Article

\title{
Energy Efficient Rapid Removal of Arsenic in an Electrocoagulation Reactor with Hybrid Fe/Al Electrodes: Process Optimization Using CCD and Kinetic Modeling
}

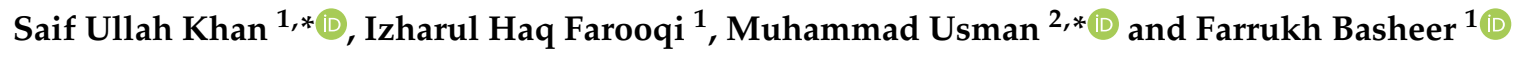 \\ 1 Department of Civil Engineering, Zakir Husain College of Engineering \& Technology, Aligarh Muslim \\ University, Aligarh 202001, India; farooqi_izhar@yahoo.com (I.H.F.); farrukhbasheer.cv@amu.ac.in (F.B.) \\ 2 Institute for Water Resources and Water Supply, Hamburg University of Technology, \\ Am Schwarzenberg-Campus 3, 20173 Hamburg, Germany \\ * Correspondence: saif07amu@gmail.com (S.U.K.); muhammad.usman@tuhh.de (M.U.)
}

Received: 31 August 2020; Accepted: 13 October 2020; Published: 16 October 2020

check for updates

\begin{abstract}
Threats due to insufficient, inadequate and costlier methods of treating contaminants such as arsenic have emphasized the significance of optimizing and managing the processes adopted. This study was aimed at the complete elimination of arsenic from an aqueous medium with minimum energy consumption using the electrocoagulation process. Arsenic removal around $95 \%$ was rapidly attained for optimized conditions having a $\mathrm{pH}$ of 7, $0.46 \mathrm{~A}$ current intensity, $10 \mathrm{mg} / \mathrm{L}$ initial concentration and only $2 \mathrm{~min}$ of applied time duration using the energy of 3.1 watt-hour per gram of arsenic removed. Low values of applied current for longer durations resulted in the complete removal of arsenic with low energy consumption. Various hydroxide complexes including ferrous hydroxide and ferric hydroxide assisted in the removal of arsenic by adsorption along with co-precipitation. Surface models obtained were checked and found with a reasonably good fit having high values of coefficient of determination of 0.933 and 0.980 for removal efficiency and energy consumption, respectively. Adsorption was found to follow pseudo-first-order kinetics. Multivariate optimization proved it as a low-cost effective technology having an operational cost of 0.0974 Indian rupees (equivalent to USD 0.0013) per gram removal of arsenic. Overall, the process was well optimized using CCD based on response surface methodology.
\end{abstract}

Keywords: arsenic removal; response surface methodology; central composite design; energy minimization; kinetic models

\section{Introduction}

Arsenic (As) is a ubiquitous element naturally occurring and widely dispersed inside the earth's crust. It enters the water reserves due to various natural processes such as mineral dissolutions, weathering of rocks and anthropogenic undertakings such as manufacturing, mining and agriculture [1]. Almost 140 million people all around the globe have been affected by arsenic, most of them from Asia [2]. The situation and scenario in several states of India, specifically West Bengal and almost the entirety of Bangladesh, are highly disturbing. Ingesting inorganic arsenic is known for causing cancers related to skin, lungs and urinary bladder, besides other non-cancerous effects. To minimize arsenic-related health problems, most of the regulatory authorities recommended a more stringent limit of $10 \mu \mathrm{g} / \mathrm{L}$ in drinking water supplies [3].

Arsenic exist both in inorganic as well as organic forms. In aqueous environments, inorganic As species are highly prevalent among the two. Inorganic As in water is mostly found in two 
oxidation states: arsenate $(\mathrm{As}(\mathrm{V}))$ and arsenite $(\mathrm{As}(\mathrm{III}))$, of which $\mathrm{As}(\mathrm{III})$ is more soluble and poisonous [4]. In oxidizing environments, $\mathrm{H}_{2} \mathrm{AsO}_{4}{ }^{-}$and $\mathrm{HAsO}_{4}{ }^{2-}$ are the major negatively charged arsenic species with $\mathrm{H}_{2} \mathrm{AsO}_{4}{ }^{-}$dominantly found at $\mathrm{pH}$ lower than 6.9 , while $\mathrm{HAsO}_{4}{ }^{2-}$ occurs at higher $\mathrm{pH}$ values. Under reducing environments, the uncharged $\mathrm{H}_{3} \mathrm{AsO}_{3}$ dominates at $\mathrm{pH}$ less than $9[1,5]$. Its geochemistry depends upon various factors, such as oxidation state, speciation and redox transformations.

Researchers have adopted various methods for the removal of toxic metals, such as ion exchange, chemical reduction, reverse osmosis, modified coagulation/filtration, adsorption and electrochemical means [6-8]. However, these conventional approaches have several drawbacks, including low efficiency, the need for special chemicals, high energy requirements, increased cost and the problems of sludge handling and disposal.

With advancements and ongoing technological developments, electrochemical-assisted techniques have garnered attention of researchers as environmentally-friendly and sustainable processes. Among these, electrocoagulation (EC) is the most widely adopted wastewater treatment process [9]. It voids sophisticated facilities and excessive use of chemicals and results in very low sludge production compared to other processes [10]. Compared with plain coagulation processes, EC has various advantages, such as continuous coagulant dissipation from the anode, effective dispersion of precipitated flocs with better adsorptive removal and the production of sludge with better settleability [11]. Several studies have been carried out using electrocoagulation in treating various water streams [12-16]. Most of the EC studies on arsenic removal used either iron or aluminum electrodes due to cost concerns as well as high removal efficiencies. Studies on the use of these combined electrode materials are very rare but may prove in finding alternatives to conventional procedures [17]. Among the two, arsenate removal is comparatively much easier than arsenite removal $[18,19]$. Therefore, for efficient As(III) removal, oxidation of As(III) to As(V) needs to be carried out, which is easily achieved in the electrocoagulation process.

\section{Removal Mechanism and Chemistry inside the EC Reactor}

Arsenic removal by electrocoagulation involves several reactions inside the reactor occurring simultaneously, such as in situ generation of coagulant because of anode dissolution and production of hydrogen gas at the cathode. The pollutant removal mechanism in electrocoagulation undertakes electrochemical oxidation of the anode with the production of coagulating ions followed by destabilization and agglomeration to form flocs [20]. The insoluble metal hydroxide formed removes the target pollutant by enmeshing it in the floc formed. The hydroxyl ions produced at the cathode react simultaneously with the metallic ions from the anode to form metallic hydroxides [8]. Moreover, the hydroxide ions produced at the cathode increase the $\mathrm{pH}$ of water, persuading metal ions to precipitate in the form of corresponding hydroxides along with co-precipitation of aluminum hydroxides.

The $\mathrm{pH}$ of the medium has a dominant role to play in the targeted removal of contaminants in the EC process, as the speciation of aluminum, ferrous and ferric ion depends upon $\mathrm{pH}$. Various forms of ferrous ions are dominant in different $\mathrm{pH}$ ranges. For instance, $\mathrm{Fe}(\mathrm{OH})^{+}, \mathrm{Fe}(\mathrm{OH})_{2}$ and $\mathrm{Fe}(\mathrm{OH})_{3}{ }^{-}$predominate at $\mathrm{pH}$ values below 11 and 11.5 and above 1.5, respectively. Similar is the case with different forms of ferric ions having a predominance of $\mathrm{Fe}^{3+}, \mathrm{Fe}(\mathrm{OH})^{2+}, \mathrm{Fe}(\mathrm{OH})_{2}{ }^{+}$and $\mathrm{Fe}(\mathrm{OH})_{3} \mathrm{Fe}(\mathrm{OH})_{4}{ }^{-}$in a medium at $\mathrm{pH}$ below 3, 3-4, 4-6 and 6-9.5, and above 9.5, respectively. In the same way, aluminum ions generated by electrochemical oxidation form various monomeric and polymeric species of aluminum hydroxyl complexes, such as $\mathrm{Al}(\mathrm{OH})_{3}, \mathrm{Al}(\mathrm{OH})_{4}{ }^{-}$, etc. Various forms of arsenate $\left(\mathrm{H}_{3} \mathrm{AsO}_{4}, \mathrm{H}_{2} \mathrm{AsO}_{4}{ }^{-}, \mathrm{HAsO}_{4}{ }^{2-}\right.$ and $\left.\mathrm{AsO}_{4}{ }^{3-}\right)$ and arsenite $\left(\mathrm{H}_{3} \mathrm{AsO}_{3}, \mathrm{H}_{2} \mathrm{AsO}_{3}{ }^{-}\right.$, $\mathrm{HAsO}_{3}{ }^{2-}$ and $\mathrm{AsO}_{3}{ }^{3-}$ ) get adsorbed over the insoluble iron and aluminum hydroxides depending upon their surface charges and affinity between the two [21]. The overall mechanism in arsenic removal involves oxidation of $\mathrm{As}(\mathrm{III})$ to $\mathrm{As}(\mathrm{V})$ followed by adsorption/co-precipitation over the available $\mathrm{Fe}(\mathrm{III})$ hydroxide in the medium. The $\mathrm{OH}^{-}$in the metal hydroxide gets substituted by arsenic ions, as shown 
in Equations (1)-(4). This mechanism of co-precipitation and adsorption of arsenic over $\mathrm{Fe}(\mathrm{OH})$ and $\mathrm{Al}(\mathrm{OH})$ may be described in the following equations $[17,22]$ :

$$
\begin{gathered}
2 \mathrm{FeOOH}+\mathrm{H}_{2} \mathrm{AsO}_{4}{ }^{-} \rightarrow(\mathrm{FeO})_{2} \mathrm{HAsO}_{4}{ }^{-}+\mathrm{H}_{2} \mathrm{O}+\mathrm{OH}^{-} \\
3 \mathrm{FeOOH}+\mathrm{HAsO}_{4}{ }^{2-} \rightarrow(\mathrm{FeO})_{3} \mathrm{AsO}_{4}{ }^{2-}+\mathrm{H}_{2} \mathrm{O}+2 \mathrm{OH}^{-} \\
\mathrm{AlOH}+\mathrm{HAsO}_{4}{ }^{2-} \rightarrow \mathrm{AlOAs}(\mathrm{O})_{2}(\mathrm{OH})^{-}+\mathrm{OH}^{-} \\
\mathrm{AlOH}+\mathrm{H}_{3} \mathrm{AsO}_{3} \rightarrow \mathrm{AlOH}_{2} \mathrm{As}(\mathrm{O})_{2}(\mathrm{OH})^{-}+\mathrm{H}^{+}
\end{gathered}
$$

The present study aims for multivariate optimization of the EC process in achieving rapid as well as complete removal of total arsenic along with minimum possible consumption of energy. Studies carried out so far on arsenic removal and optimizing of the EC process generally lack consideration of energy consumption as a response. Moreover, the use of a combined iron-aluminum anode in the form of a concentric electrode configuration was tried in order to consider this combined anodic effect on the performance of the reactor. Kinetics was also studied to investigate the adsorption phenomenon on the in-situ generated sludge. Process factors such as applied current, initial concentration, initial $\mathrm{pH}$ and time were experimentally varied in accordance with the design to know their effect on response variables.

\section{Materials and Methods}

A stock solution of arsenic was prepared using $\mathrm{As}_{2} \mathrm{O}_{3}$ (Merck, Darmstadt, Germany) in $2 \% \mathrm{HCl}$. Synthetic solutions of required concentrations were prepared accordingly from the stock solution. $\mathrm{pH}$ adjustments were carried out using $\mathrm{HCl}$ and $\mathrm{NaOH}$ and measured by a Hach probe. To maintain the conductivity around $1000 \mu \mathrm{S} / \mathrm{cm}$ within $5 \%$ accuracy, $\mathrm{NaCl}$ was used, and conductivity was measured by a Hach probe. Total arsenic concentration was analyzed using an atomic absorption spectrometer attached with a hydride generator assembly (Perkin Elmer PinAAcle 900F AAS, Waltham, MA, USA). For supplying current, a variable source DC power supply (SCIENTECH 4079, Indore, India) was used.

\subsection{Experimental Set-Up}

A column reactor made of Plexiglas was used comprising of anode rod at the center with the cathode in the form of mesh symmetrically placed around the anode, as schematically represented in Figure 1. The anode used was made of iron at the top and aluminum at the bottom, having a diameter of $1.6 \mathrm{~cm}$ and length of $15 \mathrm{~cm}$, while mesh placed around it had a diameter of $6.5 \mathrm{~cm}$. The reactor was connected with a DC source and agitated using a magnetic stirrer. A port at the middle of the reactor was provided to collect aliquots to be analyzed for arsenic concentrations. Three samples of aliquots were collected to report mean values according to experimental design. Conductivity for all the experimental runs was adjusted around $1000 \mu \mathrm{S} / \mathrm{cm}$ using $\mathrm{NaCl}$. The $\mathrm{pH}$ of the synthetic solutions prepared was altered before each run according to the design. 


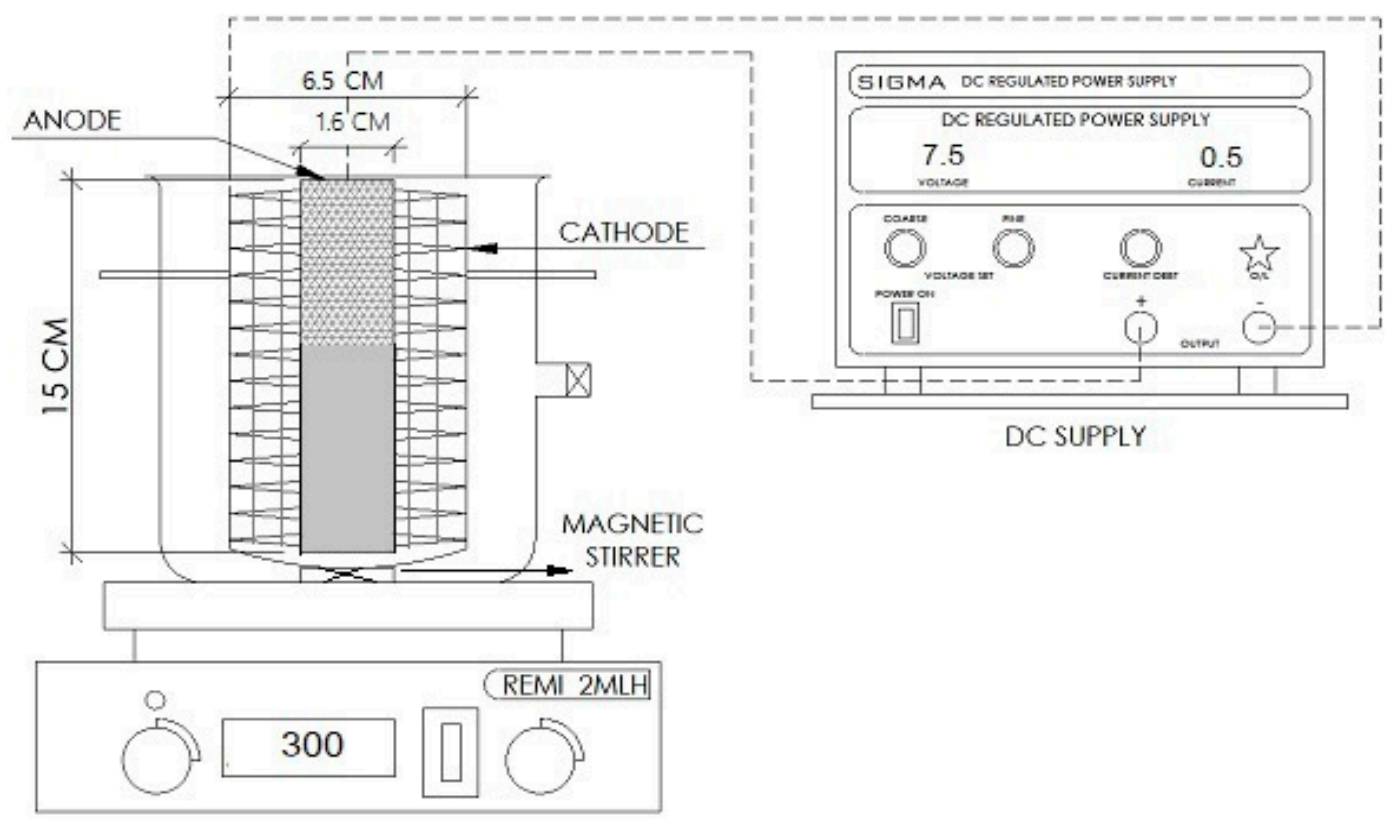

Figure 1. Schematic representation of experimental set up.

\subsection{Statistical Analysis}

Statistical methods are highly useful in designing a multivariate experiment. One factor at a time analysis of any process is inherently insufficient to determine the interactions amongst the process. Response surface methodology was therefore adopted, which is a combination of mathematical and statistical methods for establishing a relation between variables and responses [23]. One of the major benefits of such analysis is that it is easy to optimize the process by using the differential calculus to obtain the global maxima or minima for a particular set of constraints. A general second-order model equation of central composite design, commonly adopted for RSM, is given by Equation (5) as follows:

$$
y=\beta_{o}+\sum_{i=1}^{k} \beta_{i} x_{i}+\sum \sum_{i<j} \beta_{i j} x_{i} x_{j}+\sum_{i=1}^{k} \beta_{i i} x_{i}^{2}+\epsilon
$$

where, $y$ stands for response, $\left(x_{i}\right.$ and $\left.x_{j}\right)$ are independent variables, $\left(\beta_{o}, \beta_{i}, \beta_{i i}\right.$ and $\left.\beta_{i j}\right)$ are offset term, linear, quadratic and interactive coefficients, respectively.

Central composite design (CCD) was adopted, with four factors in total with each factor at 5 levels. A set of 30 runs was carried out experimentally in a random fashion for real and coded values, as shown in Table 1, for process factors having their corresponding ranges. A trial version of Design-Expert software was used for analyzing the experimental data [24]. For choosing the model and its adequacy, the results were subjected to a lack of fit and sequential sum of squares test. The fitness was determined using obtained values of $\mathrm{R}^{2}$.

Table 1. Set of coded and actual values adopted for central composite design (CCD).

\begin{tabular}{cccccccc}
\hline \multirow{2}{*}{ Parameter } & \multirow{2}{*}{ Unit } & \multirow{2}{*}{ Code } & \multicolumn{5}{c}{ Real Values } \\
\cline { 4 - 8 } & & & $-\boldsymbol{\alpha}$ & $\mathbf{- 1}$ & $\mathbf{0}$ & $\mathbf{+ 1}$ & $+\boldsymbol{\alpha}$ \\
\hline $\mathrm{pH}$ & - & $\mathrm{A}$ & 4 & 5.5 & 7 & 8.5 & 10 \\
Current & $\mathrm{amp}$ & $\mathrm{B}$ & 0.1 & 0.2 & 0.3 & 0.4 & 0.5 \\
Initial concentration & $\mathrm{mg} / \mathrm{L}$ & $\mathrm{C}$ & 4 & 6 & 8 & 10 & 12 \\
Time & $\mathrm{min}$ & $\mathrm{D}$ & 2 & 4 & 6 & 8 & 10 \\
\hline
\end{tabular}




\section{Results and Discussion}

Analysis of variance (ANOVA) was carried out to check the model acceptance. Based on ANOVA tables, non-significant terms were omitted, on the basis of $\mathrm{F}$ value, while the significant terms were acknowledged at a $95 \%$ level of confidence. Significant terms were identified for both the models based on the F values found as 20.05 and 85.2, respectively (see Tables 2 and 3). The values obtained for R-square were 0.933 and 0.980 , respectively, suggesting a decent fit for both the models, viz. arsenic removal efficiency and energy consumption.

Table 2. ANOVA for total arsenic removal model.

\begin{tabular}{|c|c|c|c|c|c|c|}
\hline Source & Sum of Squares & Df & Mean Square & F-Value & $p$-Value & \\
\hline Model & 2837.88 & 12 & 236.49 & 20.05 & $<0.0001$ & significant \\
\hline A-pH & 344.81 & 1 & 344.81 & 29.23 & $<0.0001$ & \\
\hline B-Applied current & 1150.93 & 1 & 1150.93 & 97.55 & $<0.0001$ & \\
\hline C-Initial Conc. & 141.09 & 1 & 141.09 & 11.96 & 0.003 & \\
\hline D-Time & 455.92 & 1 & 455.92 & 38.64 & $<0.0001$ & \\
\hline $\mathrm{AB}$ & 54.21 & 1 & 54.21 & 4.59 & 0.0468 & \\
\hline $\mathrm{BC}$ & 150.98 & 1 & 150.98 & 12.8 & 0.0023 & \\
\hline $\mathrm{BD}$ & 71.28 & 1 & 71.28 & 6.04 & 0.025 & \\
\hline CD & 73.49 & 1 & 73.49 & 6.23 & 0.0231 & \\
\hline$A^{2}$ & 201.79 & 1 & 201.79 & 17.1 & 0.0007 & \\
\hline $\mathrm{B}^{2}$ & 246.73 & 1 & 246.73 & 20.91 & 0.0003 & \\
\hline$C^{2}$ & 26.87 & 1 & 26.87 & 2.28 & 0.1496 & \\
\hline $\mathrm{D}^{2}$ & 19.13 & 1 & 19.13 & 1.62 & 0.22 & \\
\hline Residual & 200.56 & 17 & 11.8 & & & \\
\hline Lack of Fit & 199.23 & 12 & 16.6 & 62.2 & 0.0001 & significant \\
\hline Pure Error & 1.33 & 5 & 0.2669 & & & \\
\hline Cor Total & 3038.45 & 29 & & & & \\
\hline Standard Deviation & 3.434 & \multicolumn{2}{|c|}{$\mathrm{R}^{2}$} & 0.933 & & \\
\hline Mean & 89.761 & \multicolumn{2}{|c|}{ Adjusted $\mathrm{R}^{2}$} & 0.887 & & \\
\hline C.V.\% & 3.826 & \multicolumn{2}{|c|}{ Predicted $\mathrm{R}^{2}$} & 0.694 & & \\
\hline & & \multicolumn{2}{|c|}{ Adequate Precision } & 17.946 & & \\
\hline
\end{tabular}

Table 3. ANOVA for energy consumption model.

\begin{tabular}{|c|c|c|c|c|c|c|}
\hline Source & Sum of Squares & df & Mean Square & F-Value & $p$-Value & \\
\hline Model & 231.4 & 11 & 21.04 & 85.2 & $<0.0001$ & Significant \\
\hline A-pH & 0.8622 & 1 & 0.8622 & 3.49 & 0.078 & \\
\hline B-Applied current & 142.39 & 1 & 142.39 & 576.73 & $<0.0001$ & \\
\hline C-Initial Conc. & 15.89 & 1 & 15.89 & 64.34 & $<0.0001$ & \\
\hline D-Time & 56.85 & 1 & 56.85 & 230.27 & $<0.0001$ & \\
\hline $\mathrm{AB}$ & 0.0507 & 1 & 0.0507 & 0.2053 & 0.6559 & \\
\hline $\mathrm{BC}$ & 0.2538 & 1 & 0.2538 & 1.03 & 0.324 & \\
\hline $\mathrm{BD}$ & 12.03 & 1 & 12.03 & 48.75 & $<0.0001$ & \\
\hline $\mathrm{CD}$ & 0.0603 & 1 & 0.0603 & 0.2442 & 0.6271 & \\
\hline $\mathrm{B}^{2}$ & 2.65 & 1 & 2.65 & 10.72 & 0.0042 & \\
\hline$C^{2}$ & 0.1491 & 1 & 0.1491 & 0.6039 & 0.4472 & \\
\hline $\mathrm{D}^{2}$ & 0.1173 & 1 & 0.1173 & 0.4749 & 0.4995 & \\
\hline Residual & 4.44 & 18 & 0.2469 & & & \\
\hline Lack of Fit & 4.36 & 13 & 0.3351 & 19.18 & 0.0021 & Significant \\
\hline Pure Error & 0.0874 & 5 & 0.0175 & & & \\
\hline Cor Total & 235.85 & 29 & & & & \\
\hline Standard Deviation & 0.477 & \multicolumn{2}{|c|}{$\mathrm{R}^{2}$} & \multicolumn{3}{|l|}{0.98} \\
\hline Mean & 5.069 & \multicolumn{2}{|c|}{ Adjusted $\mathrm{R}^{2}$} & 0.971 & & \\
\hline \multirow[t]{2}{*}{ C.V.\% } & 9.413 & \multicolumn{2}{|c|}{ Predicted $R^{2}$} & 0.923 & & \\
\hline & & \multicolumn{2}{|c|}{ Adequate Precision } & 36.3741 & & \\
\hline
\end{tabular}

Actual vs. predicted values were plotted against each other to check the suitability of both the models, as shown in Figure 2. It shows a very close agreement between actual and predicted values; thus both models could be rightly used to navigate the chosen design space. 


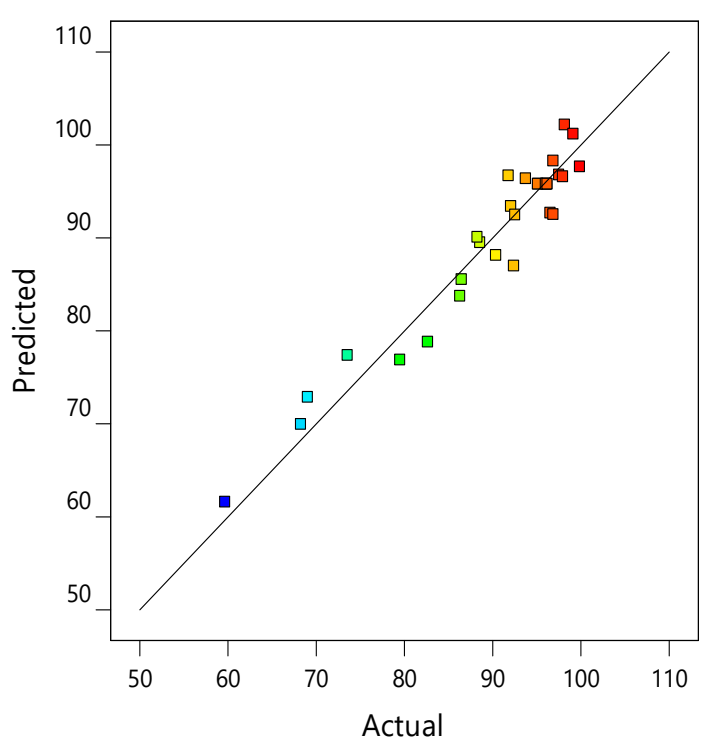

(a)

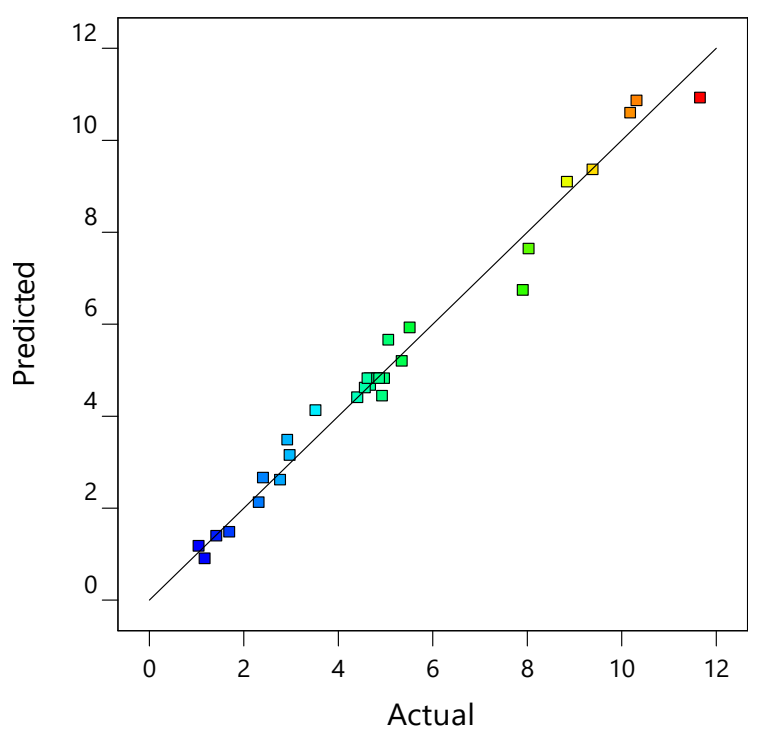

(b)

Figure 2. Actual versus predicted plots for (a) arsenic removal efficiency, (b) energy consumption per gram removal of arsenic.

Regression model equations in coded form are as follows:

$$
\begin{aligned}
& \text { Arsenic removal }(\%)=95.79+(-3.79 \mathrm{~A})+6.93 \mathrm{~B}+2.42 \mathrm{C}+4.36 \mathrm{D}+1.84 \mathrm{AB}-3.07 \mathrm{BC}- \\
& 2.11 \mathrm{BD}-2.14 \mathrm{CD}-2.71 \mathrm{~A}^{2}-2.99 \mathrm{~B}^{2}-0.98 \mathrm{C}^{2}-0.83 \mathrm{D}^{2} \\
& \text { Energy consumption }=4.81692+0.19 \mathrm{~A}+2.44 \mathrm{~B}+(-0.81 \mathrm{C})+1.54 \mathrm{D}-0.563 \mathrm{AB}+ \\
& 0.13 \mathrm{BC}+0.87 \mathrm{BD}-0.06 \mathrm{CD}+0.004 \mathrm{~A}^{2}+0.31 \mathrm{~B}^{2}+0.07 \mathrm{C}^{2}+\left(-0.06 \mathrm{D}^{2}\right)
\end{aligned}
$$

Model equations in the actual form are as follows:

Arsenic removal $(\%)=-95.29+10.67^{*} \mathrm{pH}+349.5^{*}$ Applied current $+12.99^{*}$ Initial conc. $+12.13^{*}$ Time $+12.27^{*} \mathrm{pH}^{*}$ Applied current $-15.36^{*}$ Applied current*Initial conc. $-10.55^{*}$ Applied current*Time $0.53^{*}$ Initial conc. ${ }^{*}$ Time $-1.20^{*} \mathrm{pH}^{2}-299.92^{*}$ Applied current ${ }^{2}-0.25^{*}$ Initial conc. $^{2}-0.21^{*}$ Time $^{2}$

Energy consumption $=6.52+0.21^{*} \mathrm{pH}-22.56^{*}$ Applied current $-0.79 *$ Initial conc. $-0.22^{*}$ Time $-0.37^{*} \mathrm{pH}^{*}$ Applied current $+0.63^{*}$ Applied current ${ }^{*}$ Initial conc. $+4.34^{*}$ Applied current ${ }^{*}$ Time $0.015^{*}$ Initial conc. ${ }^{*}$ Time $+0.002 \mathrm{pH}^{2}+30.80^{*}$ Applied current ${ }^{2}+0.02 *$ Initial conc. $^{2}-0.016^{*}$ Time $^{2}$

The response surface plots were obtained by plotting these multivariate regression equations for two factors at a time, keeping the other factors at central levels. The 3D surface plots obtained are shown in Figures 3 and 4. 


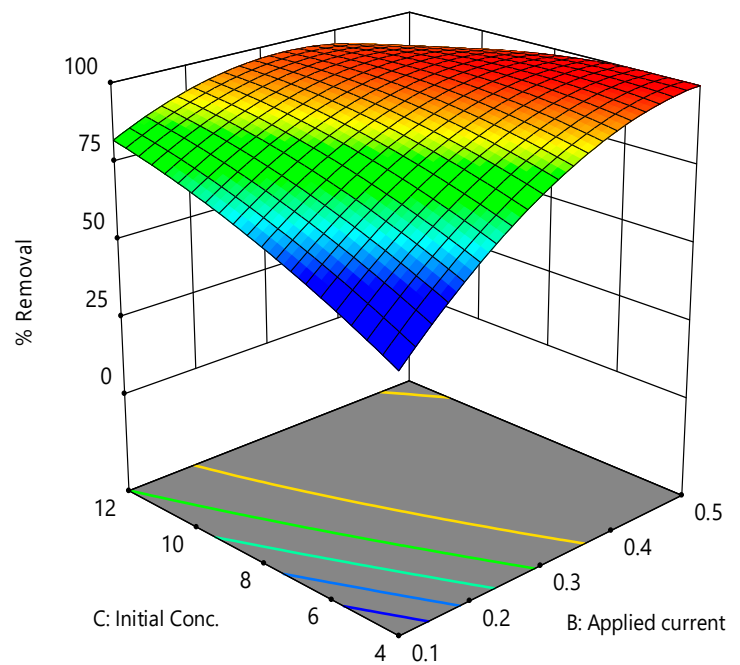

(a)

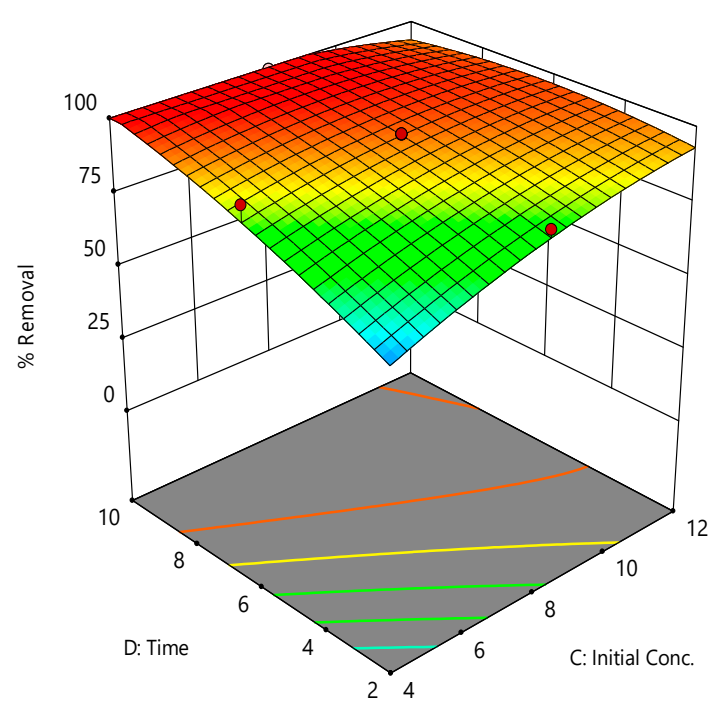

(c)

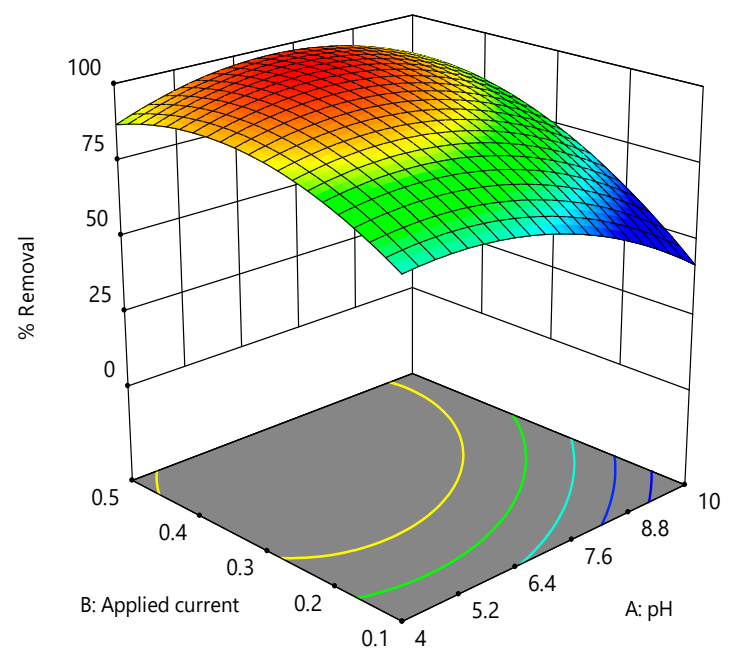

(b)

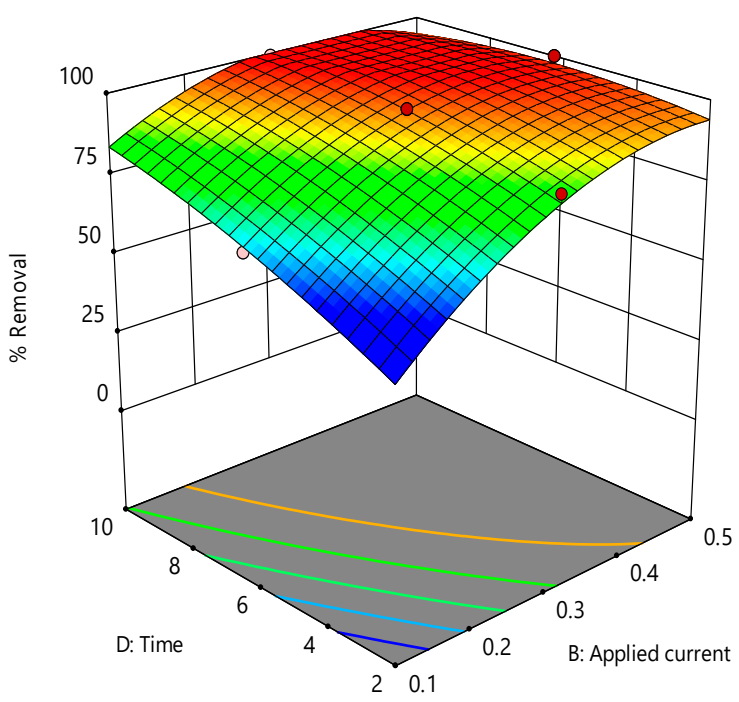

(d)

Figure 3. Surface plots (a-d) in 3D presenting the effect of all 4 interactive factors i.e., applied current, $\mathrm{pH}$, time and initial conc. on the removal efficiency of total As. 


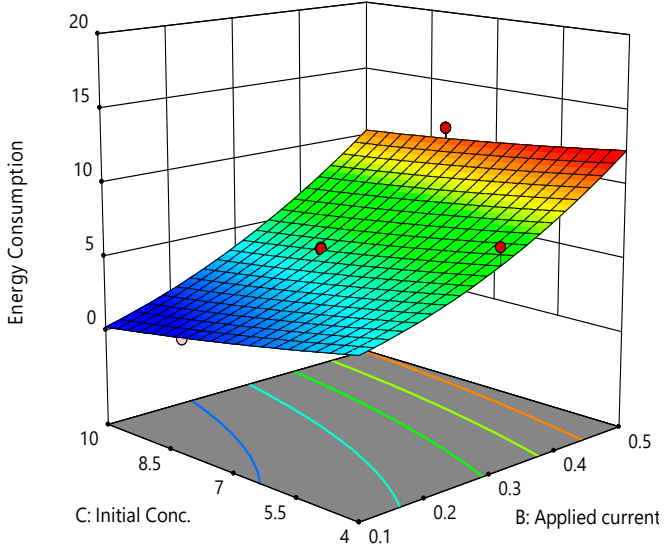

(a)

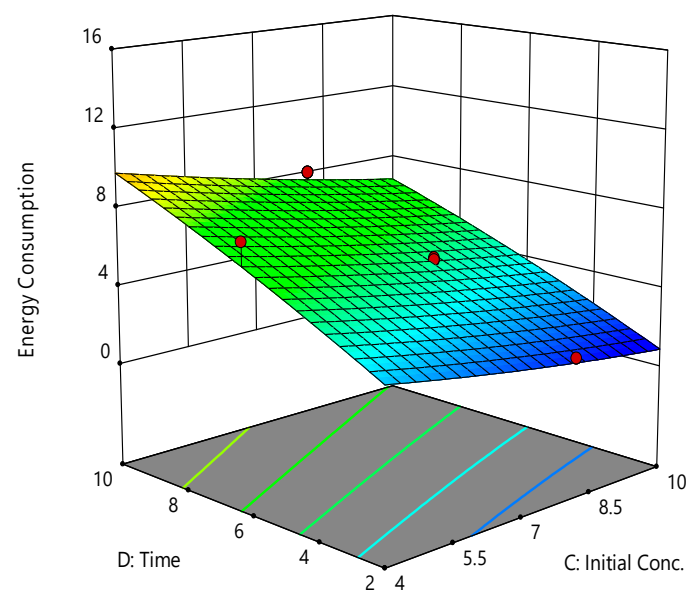

(c)

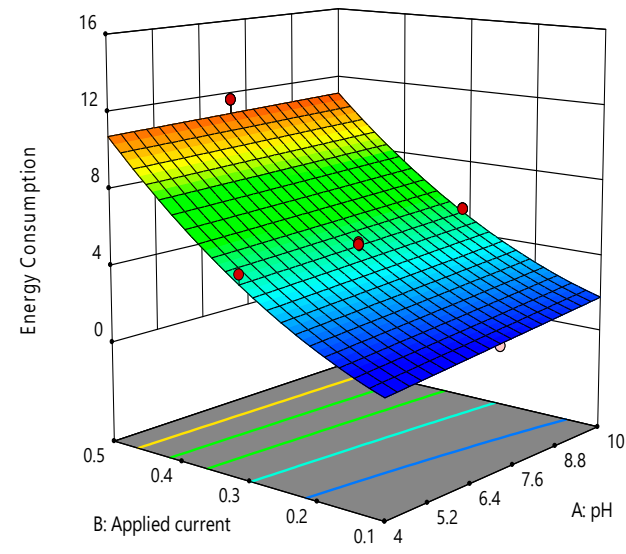

(b)

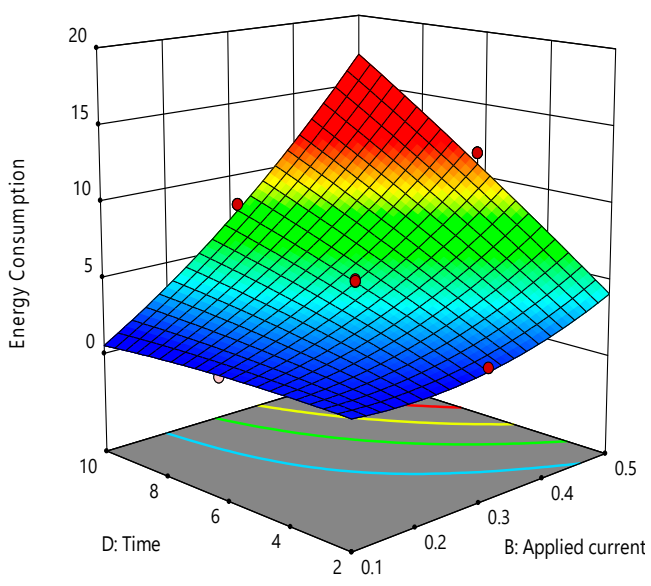

(d)

Figure 4. Surface plots in 3D presenting (a-d) the effect of all 4 interactive factors i.e., applied current, $\mathrm{pH}$, time and initial conc. on energy consumption per gm of arsenic removed in EC process.

\subsection{Optimization of the Process}

Process optimization was done using differential calculus to determine the global maxima. This was done by calculating the successive steepest slopes. Optimization was subjected to suitable constraints to resolve the final solution. Design-Expert software takes the inputs for optimization with predefined values as maximum, minimum, target, within range and none for process variable from the ranges selected for the design. The optimum conditions were obtained with a desirability function value of 0.9 .

The process optimization was kept at "target" $100 \%$ removal of total arsenic with "minimized" energy consumption and the process factors set "within range". Theoretical optimum conditions obtained were confirmed by performing three experiments at these values to compare the theoretical and experimental results showing proximity among the two. This similarity, as shown in Table 4, suggests that RSM can be suitably used for optimization. 
Table 4. Optimal values of chosen parameters.

\begin{tabular}{ccc}
\hline Parameter & Optimal Values & Average Experimental Values \\
\hline \% Removal & 94.5 & 95 \\
Energy consumption & 3.1 & 3.26 \\
pH & 7 & 7 \\
Current & 0.46 & 0.46 \\
Initial concentration & 10 & 10 \\
Time & 2 & 2 \\
\hline
\end{tabular}

\subsection{Effect of Process Parameters}

\subsubsection{Current Applied}

In any electrochemical process, current applied is the most significant parameter [25]. The supplied current determines the dissipation of metal ions at the anode; thus, the EC process gets considerably affected [26]. A number of experiments were carried out according to the CCD design, with current varied from 0.1 to $0.5 \mathrm{~A}$. According to Faraday's law, arsenic removal increases upon increasing the applied current, as depicted from 3D plots shown in Figure 3a,d, due to higher anodic dissolution resulting in excessive formation of coagulant [27]. From the 3D plots, for longer time durations even at low applied current, sufficient removal efficiency was achieved due to slow but sufficient dissipation of the anode. In this way applied current remains a dominating factor for arsenic removal.

\subsubsection{Initial $\mathrm{pH}$}

Removal of arsenic by electrocoagulation is significantly affected by $\mathrm{pH}$ of the solution, as it is one of the deterministic factors affecting the process [28]. $\mathrm{pH}$ affects the species distribution, surface charge of arsenic and metal oxides formed in the EC process [29]. Solubility of both metal hydroxides and arsenic depends on the chemistry of the aqueous medium. Positively charged colloid particles of ferrous hydroxide and ferric hydroxide are generated starting from $\mathrm{pH}$ values of about 7.0 and 3.0, respectively. However, when $\mathrm{pH}$ increases toward a highly basic nature, the amounts of ferric hydroxide decrease substantially, as also seen from the speciation diagram of Fe (III) with respect to $\mathrm{pH}$ [8]. From the 3D plot (Figure 3b), it can be inferred that arsenic removal efficiency was almost constant in the $\mathrm{pH}$ range 4 to 7 , but the removal declined as $\mathrm{pH}$ increased further in the basic range due to the fact that available iron and aluminum hydroxides were not sufficient for the adsorption of arsenate anions $\left(\mathrm{H}_{2} \mathrm{AsO}_{4}{ }^{-}\right.$and $\left.\mathrm{HAsO}_{4}{ }^{2-}\right)$, which were present in abundance in this $\mathrm{pH}$ range.

\subsubsection{Application Time}

Time duration of reactions occurring inside the reactor predominantly affected the EC process, resulting in higher removal efficiencies. The dissipated electrode mass obviously increased when increasing the reaction time, even with lower applied currents, as shown in the 3D plot (Figure 3d). Sufficient polymeric species are produced and available after passage of certain time duration to achieve complete removal of arsenic from the solution [30]. With experiments performed according to the central composite design chart by varying the application time from 2 to $10 \mathrm{~min}$, it was found that arsenic removal was quite rapid with around 95\% efficiency attained for initial $10 \mathrm{mg} / \mathrm{L}$ concentration just within 2 min of application time.

\subsubsection{Initial Concentration}

To explore the effect of initial arsenic concentration on removal efficiency, experiments were carried out at varying concentration values from 4 to $12 \mathrm{mg} / \mathrm{L}$ as per CCD. It was noticed from the 3D surface plots (Figure 3a,c) obtained that removal efficiency was quite low for lower values of the initial arsenic concentration, although it was comparatively high for higher values of initial arsenic. In addition, at lower values of supplied current, there was a drastic increase in efficiency with the increase in initial 
concentration. However, at higher values of applied current, there was only slight increase in efficiency. This may be attributed to the fact that with higher values of initial arsenic concentration, the probability of arsenic ions colliding with metallic hydroxides remains higher, thereby getting adsorbed over it. There are several studies found in accordance with this, affirming that removal rate per ampere is higher in the beginning of the EC process [31].

\section{Energy Consumption}

\subsection{Effect of Process Parameters on Electrical Energy Consumed}

Considering the ANNOVA Table 3, the model for energy consumption was analyzed to know the significance of chosen process parameters, with current intensity found exhibiting a major role in the overall consumption of energy

With the rise in applied current from 0.1 to $0.5 \mathrm{~A}$, the energy consumption was drastically increased, as is clear from the 3D plots (Figure $4 a, b, d$ ). A steep peak at higher current for longer time durations is also visible in Figure 4d. This is because at higher current values, complete removal of arsenic was achieved within the first few minutes of the process; the energy thus supplied thereafter was useless and computed to be surplus. Therefore, to keep the energy consumption minimal, small current for longer durations seems to be the optimum solution in order to attain higher efficiencies, thereby achieving the objective with minimum cost incurred. An almost similar peak was obtained in Figure $4 a$, with huge energy consumption per gram removal of arsenic at lower initial arsenic concentrations and larger values of applied current. This may be attributed to the fact that arsenic removal, especially at lower concentrations, was achieved quite early in the process, as shown in the $3 \mathrm{D}$ plot, rendering the energy supplied for the later part of the time interval unnecessary. This resulted in the unsolicited increase in the energy consumption per gram removal of arsenic.

\subsection{Computing Energy and Operational Cost}

Electrical energy consumed in removing arsenic using electrocoagulation was computed by the following formulas:

Consumption of energy in unit removal of target metal (Joule/gram):

$$
\frac{\mathrm{EIT} \times 60}{(\mathrm{Co}-\mathrm{C}) \mathrm{V}}
$$

Consumption of energy in unit removal of target metal (Watt-h/gram):

$$
\frac{\mathrm{EIT} \times 60}{(\mathrm{Co}-\mathrm{C}) \mathrm{V}} \times 2.778 \times 10^{-4}
$$

where $\mathrm{E}, \mathrm{I}, \mathrm{t}, \mathrm{V}, \mathrm{C}_{\mathrm{o}}$ and $\mathrm{C}$ have their usual abbreviations as volts, ampere, minutes, volume in liters and initial and final concentrations, respectively.

Operational cost of the EC process is estimated mainly by considering electrode cost and electricity charges incurred, ignoring factors such as sludge management and maintenance. Thus operational $\operatorname{cost}\left(\mathrm{C}_{\mathrm{o}}\right)$ is calculated using the following equation:

$$
\mathrm{C}_{\mathrm{o}}=\mathrm{C}_{\text {electrode }}+\mathrm{C}_{\text {energy }}
$$

where $\mathrm{C}_{\text {electrode }}$ and $\mathrm{C}_{\text {energy }}$ are costs accounted for cost of electrode and domestic electricity consumption rates, respectively.

The dissipated mass from electrodes is computed according to Faraday's law (Equation (11));

$$
\mathrm{M}=\frac{\mathrm{I} \times \mathrm{M} \times \mathrm{T}}{\mathrm{Z} \times \mathrm{F}}
$$


The assumed dissoluted mass of the anode was found to be $0.0426 \mathrm{~g}$ per run at optimized conditions. Considering the residential electricity rate norms, the cost incurred will be 0.0512 Indian rupees. Considering the current local market price of iron/aluminum in India, the costs incurred will be 0.0462 Indian rupees. Thus summing these two, the total operational cost at optimized conditions is estimated to Rs 0.0974 (equivalent to USD 0.0013) per gram of arsenic removed.

\section{Adsorption Kinetics}

Three experimental runs were conducted by varying initial concentrations at 60,80 and $100 \mathrm{mg} / \mathrm{L}$ for the optimized condition with $\mathrm{pH} 7$, investigating the kinetics of adsorptive removal of arsenic. Experimentally obtained results were analyzed and assessed according to pseudo-first-order and second-order kinetics [32,33]. The equations used are as follows (see Equations (12) and (13)):

$$
\begin{gathered}
\ln \left(\mathrm{q}_{\mathrm{e}}-\mathrm{q}\right)=\ln \left(\mathrm{q}_{\mathrm{e}}\right)-\mathrm{k}_{1} \mathrm{t} \\
\frac{\mathrm{t}}{\mathrm{q}}=\frac{1}{\mathrm{k}_{2} \mathrm{q}_{\mathrm{e}}^{2}}+\frac{\mathrm{t}}{\mathrm{q}_{\mathrm{e}}}
\end{gathered}
$$

where $\mathrm{q}$ is adsorption capacity at any time " $\mathrm{t}$ ", $\mathrm{q}_{\mathrm{e}}$ is adsorption capacity at equilibrium, and $\mathrm{k}_{1}$ and $\mathrm{k}_{2}$ are pseudo-first-order and second-order rate constants, respectively.

Both models were evaluated by correlation coefficients for suitability along with kinetic factors. The values of parameters as derived are tabulated in Table 5. From the kinetic analysis it is evident that the pseudo-first-order model fit better than the second-order, having values of $R^{2}$ very close to 1 .

\begin{tabular}{|c|c|c|c|c|c|c|c|}
\hline \multirow{2}{*}{$\begin{array}{c}\mathrm{C}_{\mathrm{o}} \\
\left(\mathrm{mg} \mathrm{L}^{-1}\right)\end{array}$} & \multirow{2}{*}{$\underset{(\mathrm{mg} / \mathrm{g})}{\mathrm{q}_{\mathrm{e}}(\text { Experimental) }}$} & \multicolumn{3}{|c|}{ Pseudo-First-Order } & \multicolumn{3}{|c|}{ Pseudo-Second-Order } \\
\hline & & $\begin{array}{c}\mathrm{q}_{\mathrm{e}} \text { (Calculated) } \\
(\mathrm{mg} / \mathrm{g})\end{array}$ & $\mathrm{K}_{1}\left(\min ^{-1}\right)$ & $\mathbf{R}^{2}$ & $\begin{array}{c}\mathrm{q}_{\mathrm{e}} \text { (Calculated) } \\
(\mathrm{mg} / \mathrm{g})\end{array}$ & $\begin{array}{c}\mathrm{K}_{2}\left(\times 10^{-5}\right) \\
\mathrm{g} \mathrm{mg}^{-1} \min ^{-1}\end{array}$ & $\mathbf{R}^{2}$ \\
\hline 100 & 893.568 & 805.874 & 0.0342 & 0.963 & 1352 & 1.878 & 0.928 \\
\hline 80 & 729.294 & 636.262 & 0.0418 & 0.954 & 986.269 & 3.417 & 0.952 \\
\hline 60 & 590.425 & 543.428 & 0.0325 & 0.972 & 816.354 & 2.916 & 0.941 \\
\hline
\end{tabular}

Table 5. Values of kinetic constants and coefficients for various kinetic models.

\section{Conclusions}

Rapid removal of arsenic with low energy consumption was successfully achieved by optimizing the electrocoagulation process using CCD based on response surface methodology. Within a short duration of only $2 \mathrm{~min}$, removal efficiency up to $95 \%$ was attained with 3.1 watt-hour of electrical energy consumed for per gram of arsenic removed. The surface models obtained for removal efficiency and energy consumption were found with a reasonable good fit, having high values of coefficient of determination of 0.93 and 0.98 , respectively. The roles of initial $\mathrm{pH}$, applied current, time duration and initial metal concentration were explored along with insights into electrocoagulation mechanisms and formation of various metal complexes responsible for adsorptive removal of arsenic. Among the process factors affecting the EC process, applied current was found to be most significant with the amount of iron and aluminum getting increasingly oxidized, with sufficient quantity of coagulant produced at higher values of applied current. However, low values of applied current for longer durations resulted in low energy consumption. Kinetic studies carried out indicated adsorption following a pseudo-first-order nature. Operating cost of the process was computed to be USD 0.0013 per gram of arsenic removed for the optimized run. Overall the results proved that optimization of EC process using CCD resulted in rapid, efficient and cost effective removal of arsenic from aqueous solution.

Author Contributions: Conceptualization, methodology, investigation, writing-original draft and review of the final manuscript, S.U.K.; formal analysis, S.U.K and M.U.; resources, supervision and review, I.H.F.; visualization, M.U; review and editing, M.U.; resources and review, F.B. All authors have read and agreed to the published version of the manuscript.

Funding: This research received no external funding. 
Acknowledgments: Khan is thankful for the academic support and resources of the Department of Civil Engineering, Zakir Husain College of Engineering and Technology, Aligarh Muslim University, India. We acknowledge support for the open access fee by Hamburg University of Technology (TUHH) in the funding program Open Access Publishing.

Conflicts of Interest: The authors declare no conflict of interest.

\section{References}

1. Smedley, P.L.; Kinniburgh, D.G. A review of the source, behaviour and distribution of arsenic in natural waters. Appl. Geochem. 2002, 17, 517-568. [CrossRef]

2. Podgorski, J.; Berg, M. Global threat of arsenic in groundwater. Science 2020, 368, 845-850. [CrossRef] [PubMed]

3. Usman, M.; Katsoyiannis, I.; Rodrigues, J.H.; Ernst, M. Arsenate removal from drinking water using by-products from conventional iron oxyhydroxides production as adsorbents coupled with submerged microfiltration unit. Environ. Sci. Pollut. Res. 2020, 1-13. [CrossRef] [PubMed]

4. Usman, M.; Katsoyiannis, I.; Mitrakas, M.; Zouboulis, A.; Ernst, M. Performance evaluation of small sized powdered ferric hydroxide as arsenic adsorbent. Water 2018, 10, 957. [CrossRef]

5. Yan, X.-P.; Kerrich, R.; Hendry, M.J. Distribution of arsenic(III), arsenic(V) and total inorganic arsenic in porewaters from a thick till and clay-rich aquitard sequence, Saskatchewan, Canada. Geochim. Cosmochim. Acta 2000, 64, 2637-2648. [CrossRef]

6. Usman, M.; Zarebanadkouki, M.; Waseem, M.; Katsoyiannis, I.A.; Ernst, M. Mathematical modeling of arsenic (V) adsorption onto iron oxyhydroxides in an adsorption-submerged membrane hybrid system. J. Hazard. Mater. 2020, 400, 123221. [CrossRef] [PubMed]

7. Kabir, F.; Chowdhury, S. Arsenic removal methods for drinking water in the developing countries: Technological developments and research needs. Environ. Sci. Pollut. Res. 2017, 24, 24102-24120. [CrossRef] [PubMed]

8. Khan, S.U.; Farooqi, I.H.; Ayub, S. Studies on application of Fe based binary oxide nanoparticles for treatment of lead (Pb2+) contaminated water-A batch study. Mater. Today Proc. 2017, 4, 9650-9655. [CrossRef]

9. Khan, S.U.; Islam, D.T.; Farooqi, I.H.; Ayub, S.; Basheer, F. Hexavalent chromium removal in an electrocoagulation column reactor: Process optimization using CCD, adsorption kinetics and $\mathrm{pH}$ modulated sludge formation. Process Saf. Environ. Prot. 2019, 122, 118-130. [CrossRef]

10. Hashim, K.S.; Shaw, A.; Al Khaddar, R.; Pedrola, M.O.; Phipps, D. Iron removal, energy consumption and operating cost of electrocoagulation of drinking water using a new flow column reactor. J. Environ. Manag. 2017, 189, 98-108. [CrossRef] [PubMed]

11. Mateen, Q.S.; Khan, S.U.; Islam, D.T.; Khan, N.A.; Farooqi, I.H. Copper (II) removal in a column reactor using electrocoagulation: Parametric optimization by response surface methodology using central composite design. Water Environ. Res. 2020, 92, 1350-1362. [CrossRef] [PubMed]

12. Hashim, K.S.; Al Khaddar, R.; Jasim, N.; Shaw, A.; Phipps, D.; Kot, P.; Pedrola, M.O.; Alattabi, A.W.; Abdulredha, M.; Alawsh, R. Electrocoagulation as a green technology for phosphate removal from river water. Sep. Purif. Technol. 2019, 210, 135-144. [CrossRef]

13. Khan, S.U.; Mahtab, M.S.; Farooqi, I.H. Enhanced lead (II) removal with low energy consumption in an Electrocoagulation column employing concentric electrodes: Process Optimization by RSM using CCD. Int. J. Environ. Anal. Chem. 2020, in press.

14. Oden, M.K.; Sari-Erkan, H. Treatment of metal plating wastewater using iron electrode by electrocoagulation process: Optimization and process performance. Process Saf. Environ. Prot. 2018, 119, 207-217. [CrossRef]

15. Deghles, A.; Kurt, U. Treatment of tannery wastewater by a hybrid electrocoagulation/electrodialysis process. Chem. Eng. Process. Process Intensif. 2016, 104, 43-50. [CrossRef]

16. Aziz, A.R.A.; Asaithambi, P.; Daud, W.M.A.B.W. Combination of electrocoagulation with advanced oxidation processes for the treatment of distillery industrial effluent. Process Saf. Environ. Prot. 2016, 99, 227-235. [CrossRef]

17. Kobya, M.; Akyol, A.; Demirbas, E.; Oncel, M.S. Removal of arsenic from drinking water by batch and continuous electrocoagulation processes using hybrid Al-Fe plate electrodes. Environ. Prog. Sustain. Energy 2014, 33, 131-140. [CrossRef] 
18. Wan, W.; Pepping, T.J.; Banerji, T.; Chaudhari, S.; Giammar, D.E. Effects of water chemistry on arsenic removal from drinking water by electrocoagulation. Water Res. 2011, 45, 384-392. [CrossRef]

19. Lakshmanan, D.; Clifford, D.A.; Samanta, G. Comparative study of arsenic removal by iron using electrocoagulation and chemical coagulation. Water Res. 2010, 44, 5641-5652. [CrossRef]

20. Vasudevan, S.; Oturan, M.A. Electrochemistry: As cause and cure in water pollution-An overview. Environ. Chem. Lett. 2014, 12, 97-108. [CrossRef]

21. Nidheesh, P.V.; Singh, T.S.A. Arsenic removal by electrocoagulation process: Recent trends and removal mechanism. Chemosphere 2017, 181, 418-432. [CrossRef] [PubMed]

22. Lacasa, E.; Cañizares, P.; Sáez, C.; Fernández, F.J.; Rodrigo, M.A. Removal of arsenic by iron and aluminium electrochemically assisted coagulation. Sep. Purif. Technol. 2011, 79, 15-19. [CrossRef]

23. Montgomery, D.C. Design and Analysis of Experiments; John wiley \& sons: Hoboken, NJ, USA, 2017.

24. Whitcomb, P.J.; Anderson, M.J. RSM Simplified: Optimizing Processes Using Response Surface Methods for Design of Experiments; CRC Press: Boca Raton, FL, USA, 2004.

25. Abdulhadi, B.A.; Kot, P.; Hashim, K.S.; Shaw, A.; Al Khaddar, R. Influence of current density and electrodes spacing on reactive red 120 dye removal from dyed water using electrocoagulation/electroflotation (EC/EF) process. In IOP Conference Series: Materials Science and Engineering; IOP Publishing: Najaf, Iraq, 2019; p. 12035.

26. Khan, S.U.; Asif, M.; Alam, F.; Khan, N.A.; Farooqi, I.H. Optimizing Fluoride Removal and Energy Consumption in a Batch Reactor Using Electrocoagulation: A Smart Treatment Technology. In Smart Cities-Opportunities and Challenges; Springer: Singapore, 2020; p. 767.

27. Omwene, P.I.; Çelen, M.; Öncel, M.S.; Kobya, M. Arsenic removal from naturally arsenic contaminated ground water by packed-bed electrocoagulator using $\mathrm{Al}$ and Fe scrap anodes. Process Saf. Environ. Prot. 2019, 121, 20-31. [CrossRef]

28. Mohammed, W.T.; AlJaberi, F.Y. Effecting of $\mathrm{pH}$ parameter on simulated wastewater treatment using electrocoagulation method. J. Eng. 2018, 24, 73-88. [CrossRef]

29. Song, P.; Yang, Z.; Xu, H.; Huang, J.; Yang, X.; Wang, L. Investigation of Influencing Factors and Mechanism of Antimony and Arsenic Removal by Electrocoagulation Using Fe-Al Electrodes. Ind. Eng. Chem. Res. 2014, 53, 12911-12919. [CrossRef]

30. Asaithambi, P.; Aziz, A.R.A.; Daud, W.M.A.B.W. Integrated ozone-Electrocoagulation process for the removal of pollutant from industrial effluent: Optimization through response surface methodology. Chem. Eng. Process. Process Intensif. 2016, 105, 92-102. [CrossRef]

31. Heidmann, I.; Calmano, W. Removal of $\mathrm{Cr}(\mathrm{VI})$ from model wastewaters by electrocoagulation with Fe electrodes. Sep. Purif. Technol. 2008, 61, 15-21. [CrossRef]

32. Lagrergen, S. Zur Theorie Der Sogenannten Adsorption Gelöster Stoffe Kungliga Svenska Vetenskapsakademiens. Handlingar 1898, 24, 1-39.

33. Khan, S.U.; Zaidi, R.; Hassan, S.Z.; Farooqi, I.H.; Azam, A. Application of Fe-Cu binary oxide nanoparticles for the removal of hexavalent chromium from aqueous solution. Water Sci. Technol. 2019, 74, 165-175. [CrossRef] [PubMed]

Publisher's Note: MDPI stays neutral with regard to jurisdictional claims in published maps and institutional affiliations.

(C) 2020 by the authors. Licensee MDPI, Basel, Switzerland. This article is an open access article distributed under the terms and conditions of the Creative Commons Attribution (CC BY) license (http://creativecommons.org/licenses/by/4.0/). 